\title{
AAV8-mediated gene transfer of microRNA-132 improves beta cell function in mice fed a high-fat diet
}

\author{
Niels L Mulder1, Rick Havinga', Joost Kluiver², Albert K Groen ${ }^{1,3}$ and Janine K Kruit ${ }^{1}$ \\ 1Department of Pediatrics, University of Groningen, University Medical Center Groningen, Groningen, The Netherlands \\ 2Department of Pathology and Medical Biology, University of Groningen, University Medical Center Groningen, Groningen, The Netherlands \\ 3Department of Laboratory Medicine, University of Groningen, University Medical Center Groningen, Groningen, The Netherlands
}

Correspondence should be addressed to J K Kruit: j.k.kruit@umcg.nl

\begin{abstract}
MicroRNAs have emerged as essential regulators of beta cell function and beta cell proliferation. One of these microRNAs, miR-132, is highly induced in several obesity models and increased expression of miR-132 in vitro modulates glucose-stimulated insulin secretion. The aim of this study was to investigate the therapeutic benefits of miR-132 overexpression on beta cell function in vivo. To overexpress miR-132 specifically in beta cells, we employed adeno-associated virus (AAV8)-mediated gene transfer using the rat insulin promoter in a double-stranded, self-complementary AAV vector to overexpress miR-132. Treatment of mice with dsAAV8-RIP-mir132 increased miR-132 expression in beta cells without impacting expression of miR-212 or miR-375. Surprisingly, overexpression of miR-132 did not impact glucose homeostasis in chow-fed animals. Overexpression of miR-132 did improve insulin secretion and hence glucose homeostasis in high-fat diet-fed mice. Furthermore, miR-132 overexpression increased beta cell proliferation in mice fed a high-fat diet. In conclusion, our data show that AAV8-mediated gene transfer of miR-132 to beta cells improves beta cell function in mice in response to a high-fat diet. This suggests that increased miR-132 expression is beneficial for beta cell function during hyperglycemia and obesity.
\end{abstract}
Key Words
- insulin secretion
- microRNAs
- miR-132
- gene therapy

\section{Introduction}

Decreased beta cell function plays a pivotal role in the development of type 2 diabetes mellitus. Impaired beta cell function is an early step in the course of type 2 diabetes mellitus, and the onset of beta cell dysfunction seemingly occurs long before the development of hyperglycemia (Perley \& Kipnis 1967, Kahn et al. 2001). miRNAs are a recently discovered class of evolutionarily conserved short noncoding RNAs that regulate gene expression at a posttranscriptional level. miRNAs bind with imperfect complementary to 3'-UTRs of target mRNAs, causing translational repression of the target gene or degradation of the target mRNA (Bartel 2004). miRNAs are involved in a wide range of processes that includes development, apoptosis, proliferation, differentiation and regulation of metabolism. In beta cells, miRNAs have emerged as essential regulators of beta-function, beta cell proliferation and beta cell survival (Poy et al. 2009, Latreille et al. 2014, Tattikota et al. 2014, Belgardt et al. 2015).

Obesity, a major risk factor for type 2 diabetes mellitus, is known to change miRNA expression in islets 
(Zhao et al. 2009, Nesca et al. 2013). One of these miRNAs, miR-132, is of particular interest as expression of this miRNA is highly induced in islets of several obesity models (Zhao et al. 2009, Esguerra et al. 2011, Nesca et al. 2013). This obesity-related increased expression is severely reduced in diabetic-susceptible BTBR ob/ob mice (Zhao et al. 2009). Overexpression of miR-132 in rodent beta cells in vitro results in enhanced glucose-induced insulin secretion (Nesca et al. 2013, Soni et al. 2014). This study aims to investigate the therapeutic benefits of miR-132 overexpression on beta cell function in vivo. In order to overexpress miR-132 specifically in beta cells, we created an adeno-associated virus (AAV) vector containing miR-132 under control of the insulin promoter. AAV gene transfer has previously shown to efficiently and stably transduce beta cells in vivo without impacting beta cell function (Wang et al. 2006, Montane et al. 2011). Subsequently, the impact of miR-132 overexpression on beta cell function was studied in mice under normal and insulin-resistant conditions.

\section{Material and methods}

\section{Generation of viral vectors}

The dsAAV8-RIP-GFP vector was constructed on the backbone of the dsAAV8 plasmid (Nathwani et al. 2006). The original LP1 promoter and FIX-coding sequences were replaced by the rat insulin promoter (RIP) (Addgene Plasmid 15029) and enhanced green fluorescent protein (eGFP), by amplification using primers in Table 1 and using MscI BstXI and EcoRI HindIII restriction sites. The gene encoding miR-132 was amplified from chromosomal DNA from C57Bl/6J mice, using primers listed in Table 1 and cloned between the RIP and eGFP in dsAAV8-RIP-GFP, using the restriction enzymes BspEI and SbfI (New England Biolabs).

\section{AAV creation}

dsAAV viral particles were generated by triple transfection of human embryonic kidney 293 cells using the 25-kDa linear polyethylenimine (Polysciences Inc., Eppelheim, Germany) transfection method (Reed et al. 2006). AAV viral particles were purified by iodixanol gradient centrifugation as previously described (Zolotukhin et al. 1999). Viral titers were determined using quantitative PCR (qPCR) with primers specific for RIP and eGFP.

\section{Mice and in vivo virus injection}

Male C57Bl/6J wild-type, ob/ob and ob/+ mice (9-10 weeks) were obtained from the Harlan Laboratories. C57Bl/6J mice were injected with $\mathrm{AAV}$ at the age of 12 weeks. Intraductal injection was performed as described (Jimenez et al. 2011) with minor adjustments. Mice were anesthetized with isoflurane. The duodenum was isolated with the common bile duct attached. A microclamp was placed on the bile duct caudal to the liver. Using a $27 \mathrm{G}$ needle, the duodenum was punctured after which the needle was inserted to advance retrograde through the sphincter of Oddi into the common bile duct. The needle was secured in place using a ligation and $100 \mu \mathrm{L}$ PBS containing $1.4 \times 10^{11}$ viral genome particles was injected into the duct over approximately $1 \mathrm{~min}$. At $1 \mathrm{~min}$ post injection the microclamps and needle were removed. The puncture in the duodenum was closed using tissue glue. Mice received buprenorphine $(0.05 \mathrm{mg} / \mathrm{kg}$ s.c.) directly and $8 \mathrm{~h}$ after surgery. Mice were allowed to recover for 2 weeks on chow diet (RMH-B, Hope Farms, Woerden, the Netherlands), after which mice received chow or high-fat diet (60\% kcal\% fat diet, \#D12492, Research Diets Inc., New Brunswick, USA) for 4 weeks. All experiments were performed with the approval of the Ethical Committee for Animal Experiments of the University of Groningen.

\section{Primary mouse islet isolation, cell culture and in vitro insulin secretion assay}

Islets were isolated by collagenase digestion as previously described (Salvalaggio et al. 2002). Islets were rinsed and handpicked in RPMI media containing 10\% FBS after which islets were frozen immediately for RNA isolation

Table 1 Primer sequences.

\begin{tabular}{|c|c|c|}
\hline Primer name & Sequence & Gene \\
\hline sCAAV-GFP-fw & tactacgaattcaccatggtgagcaagggcgag & GFP \\
\hline scAAV-GFP-rV & tactacaagctttcacttgtacagctcgtcca & GFP \\
\hline sCAAV-RIP-fw & gtggagtcgtcgtaccgggccc & RIP \\
\hline sCAAV-RIP-rV & gttgccaggtcagtgggcatgcctgc & RIP \\
\hline Mmu-mir132-fw & gcgaaacctgcaggtccctgcgccgctgtccgcg & Mmu-mir132 \\
\hline Mmu-mir132-rv & gcgaaatccggatgccacctccgcagacacat & Mmu-mir132 \\
\hline
\end{tabular}


or cultured overnight. The following day, static insulin secretion assay was performed on size-matched islets as previously described (Brunham et al. 2007). Insulin was measured by ELISA (Mouse-Insulin Ultra-Sensitive ELISA or the Rat Insulin ELISA, Alpco, Salem, NH, USA). Rat insulinproducing INS-1E cells (provided by Dr P Maechler, Centre Médical Universitaire, Geneva, Switzerland) were cultured as previously described (Merglen et al. 2004). INS-1E cells of passage numbers 50-60 were used in our experiments. For transfection, INS-1E cells were transfected using Lipofectamine 2000 (Invitrogen) with miRNA mimics (Ambion, Life Technologies). At 2 days after transfection, glucose-stimulated insulin secretion was measured. To determine whether hyperglycemia would impact miR-132 expression levels, primary mouse islets were cultured for $24 \mathrm{~h}$ in RPMI containing $2 \mathrm{mM}, 8 \mathrm{mM}$ or $16 \mathrm{mM}$ glucose with $1 \%$ BSA with or without $0.4 \mathrm{mM}$ palmitate (SigmaAldrich).

\section{Glucose tolerance test and BrdU labeling}

Oral glucose tolerance tests were performed on 8-h fasted mice administered with $2 \mathrm{~g}$ glucose per $\mathrm{kg}$ of body weight. Blood was taken from the saphenous vein and blood glucose levels were measured using a glucometer and test strips (Life Scan). For plasma insulin levels, blood was collected using EDTA-coated capillary tubes and insulin levels were measured by ELISA (Mouse-Insulin UltraSensitive ELISA, Alpco, Salem, NH, USA). For beta cell proliferation measurements, mice were daily injected i.p. with $1 \mathrm{mg} /$ animal BrdU (Sigma-Aldrich) in PBS for 4 days before killing.

\section{Immunostaining and islet morphology analysis}

Formalin-fixed pancreatic tissues were embedded in paraffin using standard techniques. Four micrometer sections were deparaffinized, rehydrated and incubated with blocking solution. Sections were incubated overnight at $4^{\circ} \mathrm{C}$ with antibodies against insulin and glucagon (Dako), GFP (Life Technologies) and/or BrdU (Abcam), followed by secondary antibodies conjugated to FITC or Cy3 (Life Technologies). DAPI-containing mounting media (Vector Laboratories, Burlingame, CA, USA) was added to coverslips. Proliferating beta cells were identified by co-staining for BrdU and insulin. All islets in two pancreatic sections of $200 \mu \mathrm{m}$ apart were analyzed, resulting in the counting of at least 573 beta cells/mouse with $n=4$ mice per group. For beta cell area measurements, the percentage of insulin-positive area was determined using ImageScope (Aperio) from 5 to 6 evenly spaced sections per pancreas.

\section{Measurement of miRNA and mRNA expression}

Total RNA from isolated islets was isolated using the mirVana kit (Life Technologies) according to instructions. RNA quality and concentration was measured using the Biorad Experion Bioanalyzer and miRNA microarrays were run with miRNA microarrays (MirBase release 17.0) of Agilent (Santa Clara). Array images were analyzed using Agilent feature extraction software (10.7.3.1) and GeneSpring GX (Agilent). After quantile normalization, statistical significance was tested with an unpaired $t$ test followed by Benjamini-Hochberg multiple testing correction (false discovery rate: 0.01 and a fold change of at least 2). cDNA for miRNA expression measurements was synthesized using TaqMan miRNA reverse transcription kit (Life Technologies). For mature miRNA transcript expression, we used TaqMan miRNA Assays (Life Technologies). cDNA for mRNA expression measurement was synthesized using Superscript II (Life Technologies). SYBR Green PCR Master Mix (Life Technologies) was used for RT-PCR in an ABI Prism 7700 Sequence Detection System. Expression values were normalized to Gapdh for mRNA and small nucleolar (sno) RNA202 for miRNA qRT-PCR.

\section{Protein analysis}

Isolated islets were lysed in M-PER lysis buffer (Thermo Fisher Scientific). Proteins were separated by SDS-PAGE and transferred to a nitrocellulose membrane. The membrane was blocked using TBST with $2 \%$ milk and $0.5 \%$ BSA for $1 \mathrm{~h}$ at room temperature followed by incubation with the primary antibodies in TBST with $0.5 \%$ BSA for $2 \mathrm{~h}$. Primary antibodies used were anti-retinoblastoma (Santa Cruz Biotechnology), anti-CACT (Novus Biologicals), anti-actin (Sigma-Aldrich) and anti-GAPDH (Millipore). After probing with the primary antibodies, the membrane was incubated with HRP-conjugated secondary antibodies (rabbitanti-mouse HRP-conjugated, or goat-anti-rabbit HRPconjugated, Dako). Chemiluminescence was determined using SuperSignal West Dura Extended Duration Substrate buffer (Thermo Fisher Scientific) and Chemidoc (Biorad).

\section{Statistical analysis}

Graphpad Prism 6.0 was used for statistical analysis. Data are presented as Tukey's Box-and-Whiskers plot 
using median and 25th and 75th percentile intervals $\left(\mathrm{P}_{25}-\mathrm{P}_{75}\right)$. Differences between groups were calculated by Mann-Whitney test with a $P$ value of 0.05 considered significant. A two-way ANOVA, followed by Bonferroni post hoc tests, was used to evaluate the glucose tolerance tests.

\section{Results}

Leptin deficiency resulted in profound differences in miRNA profiles of ob/ob islets, with 36 miRNAs increased and 36 miRNAs decreased by >two-fold compared to control islets $(n=6$, FDR $<1 \%)$. miR-132 was one of the most induced miRNAs in ob/ob islets with a fold change of 6.2 (Fig. 1A). Using RT-PCR, we showed increased expression of miR-132 in islets of ob/ob mice, high-fat-fed mice and 14-month aged mice (Fig. 1B). As all the diabetic/ insulin-resistant models tested had elevated fasting blood glucose levels, we determined whether hyperglycemia itself regulated expression of miR-132. Indeed, miR-132 expression levels were upregulated by culturing primary mouse islets in $16 \mathrm{mM}$ glucose for $24 \mathrm{~h}$. This increase was augmented by the addition of $2 \mathrm{mM}$ palmitate (Fig. 1C). In agreement with previous data (Nesca et al. 2013, Soni et al. 2014), overexpression of miR-132 in INS1E cells resulted in increased glucose-stimulated insulin secretion (Fig. 1D). Together, these results confirm previous data showing a role for miR-132 in glucose-regulated insulin secretion in beta cells in vitro.

\section{Increased miR-132 expression result in improved insulin secretion during high-fat feeding}

To determine whether increased expression of miR-132 would increase insulin secretion in vivo, we created doublestranded adeno-associated virus serotype 8 (dsAAV8)
A

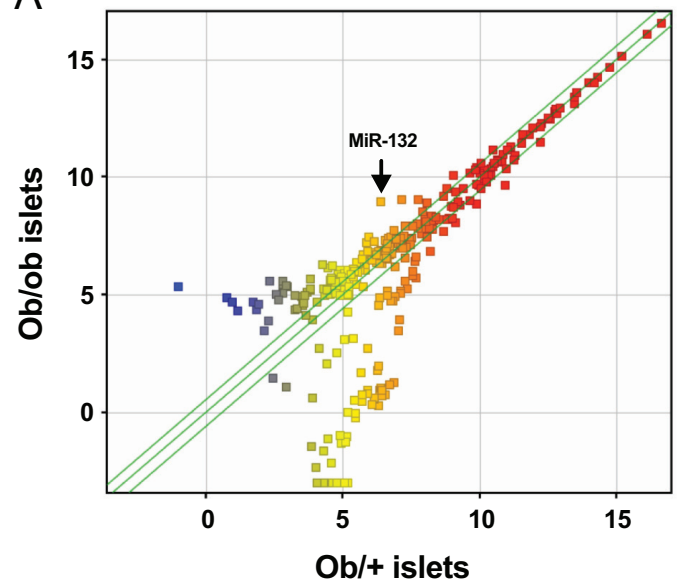

C

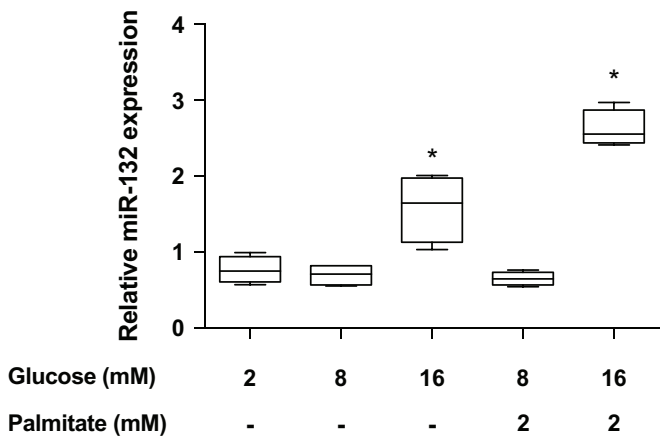

B

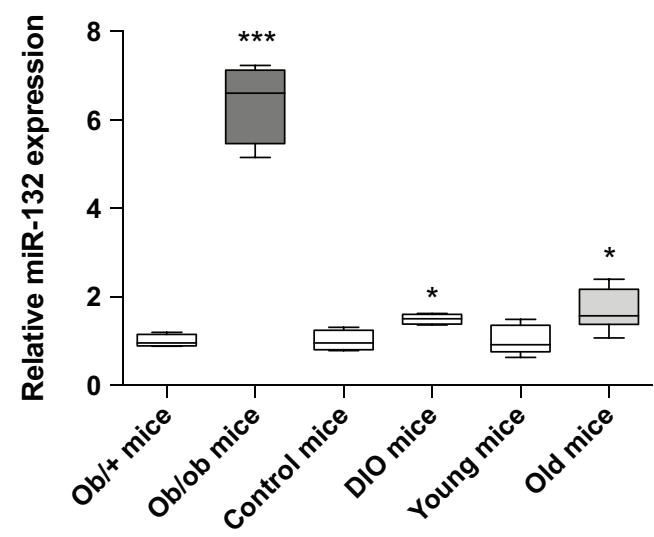

D

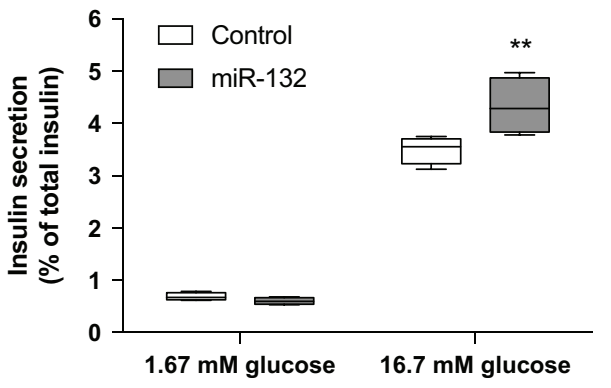

\section{Figure 1}

Hyperglycemia and obesity-induced miR-132 expression resulting in increased insulin secretion. (A) Several miRNAs were differently expressed in pancreatic islets of 12-week-old ob/ob mice $(n=6)$. (B) Increased miR-132 expression in islets isolated from ob/ob $(n=4), 10$-week high-fat diet-fed C57BI6 mice $(n=4)$ or 14 -month-old C57BI6 mice $(n=7-8)$. (C) Culture of primary islet for $24 \mathrm{~h}$ in high glucose media or media containing 2 mM palmitate-induced miR-132 expression $(n=4)$. (D) Overexpression of miR-132 in INS1E cells resulted in increased glucose-stimulated insulin secretion $(n=4)$. 
vectors containing mouse miR-132 and GFP cDNA or GFP cDNA driven by the rat insulin promoter (AAV8-RIPmir132 and AAV8-RIP-GFP). Injection of the constructs in the pancreatic duct resulted in GFP expression specifically in $\beta$-cells in the islet (Fig. 2A). Based on the GFP, the proportion of islets with GFP-positive cells was relatively high; $77 \pm 15 \%$ for control and $88 \pm 5 \%$ for AAV-RIPmiR132-treated mice. Increased expression of miR-132 was detected in isolated islets of AAV-RIP-miR132-injected animals, confirming miR-132 overexpression in $\beta$-cells in vivo (Fig. 2B). Histological examination of the pancreata of the mice showed no evidence of pancreatitis or fibrosis. Islets of both groups displayed normal morphology with the $\beta$-cells in the core and the $\alpha$-cells at the rim of the islet (Fig. 2D).

Therapeutic overexpression of miRNAs could potentially modify the processing of other cellular miRNAs transcripts due to the same processing pathways (Grimm et al. 2006). Therefore, we tested the expression of miR-375, a microRNA highly expressed in beta cells and involved in regulation of insulin secretion (Poy et al. 2004) and miR-184, a modulator of compensatory beta
A
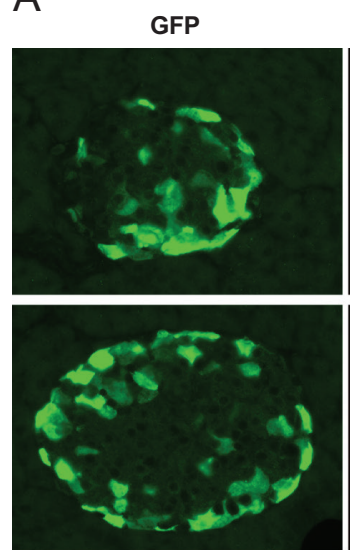

B

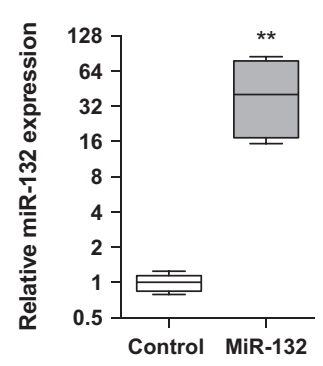

Insulin
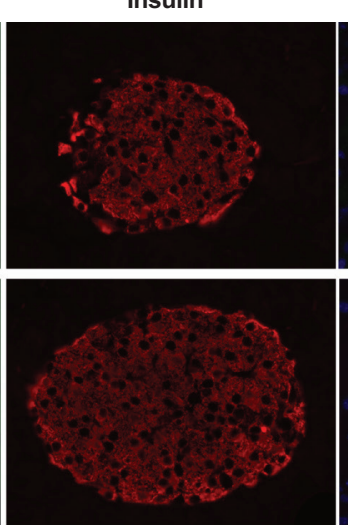

C

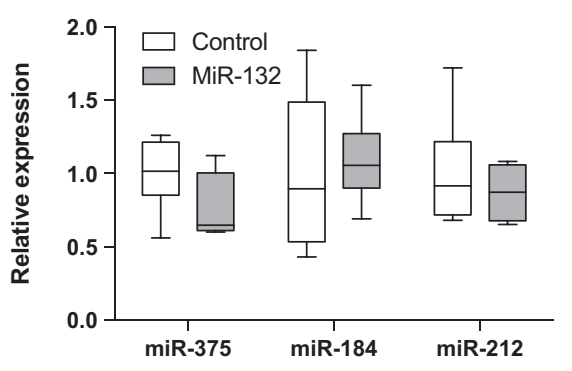

Control
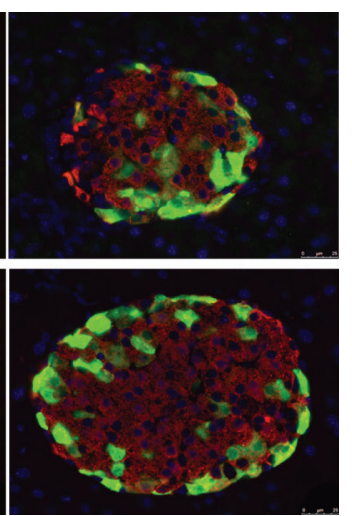

MIR-132

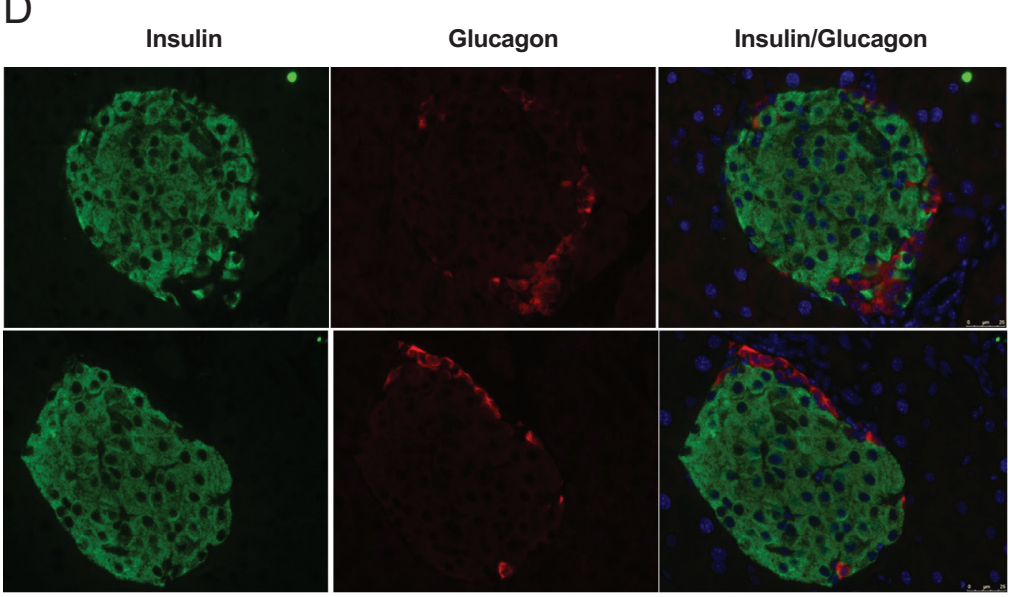

Figure 2

AAV8-mediated gene transfer resulted in miR-132 overexpression in beta cells. (A) Representative image of immunofluorescent staining against GFP (green) and insulin (red) in control AAV-RIP-GFP or AAV8-RIP-miR132-treated mice. (B) Increased expression of miR-132 in islets isolated from AAV8-RIP-miR132-treated mice compared to islets isolated from control mice $(n=4-6)$. (C) Expression of miR-375, miR-184 and miR-212 in islets was comparable between AAV8-RIP-miR132-treated and control mice $(n=4-6)$. (D) Representative image of islet morphology based immunofluorescent staining against insulin (green) and glucagon (red). 
cell expansion during insulin resistance (Tattikota et al. 2014). To exclude a possible negative feedback loop due to miR-132 overexpression on the miR-132/miR-212 cluster, miR-212 levels were determined in the islets of control and miR-132-treated mice. Overexpression of miR-132 did not impact expression of miR-212, miR-375 or miR-184 (Fig. 2C), indicating that overexpression of miR-132 did not interfere with the processing of other miRNAs.

After initial weight loss in the first week after the injection, all mice gained weight 1 month after the injection (Fig. 3A) after which glucose homeostasis was analyzed. Surprisingly, overexpression of miR-132 did not impact fasted glucose or insulin plasma levels. In addition, glucose tolerance testing showed no difference in glucose control between the animals (Fig. 3B and C). To increase the demand on beta cells, mice were put on a high-fat diet for 4 weeks. In the control AAV-RIP-GFP-treated mice, high-fat diet increased fasted glucose levels and impaired glucose tolerance (Fig. 3D). Overexpression of miR-132 specifically in beta cells, however, resulted in improved glucose tolerance compared to control mice. This was due to increased glucose-stimulated insulin secretion as measured during the glucose tolerance test (Fig. 3E) and ex vivo in isolated islets (Fig. 3F). Insulin content of isolated islets was similar in control and AAV-RIPmiR132-treated mice $(0.37 \pm 0.04 \mu \mathrm{g} /$ islet in control islets vs $0.33 \pm 0.04 \mu \mathrm{g} /$ islet in miR-132 islets; $n=6$ ). In addition, gene expressions of genes related to insulin secretion
A
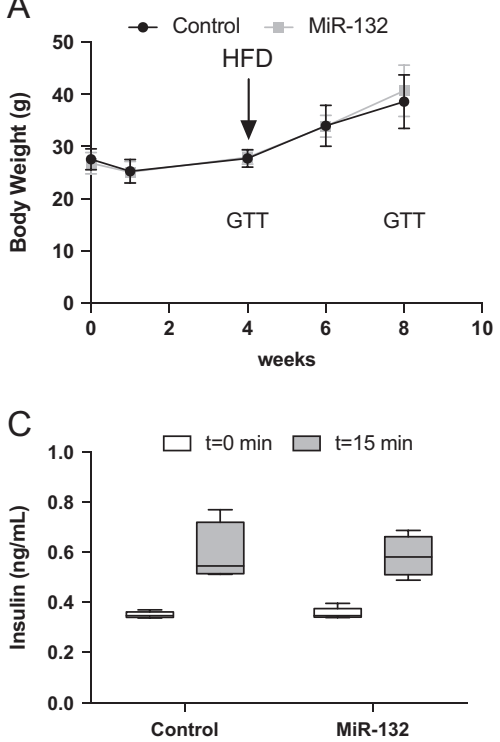

E

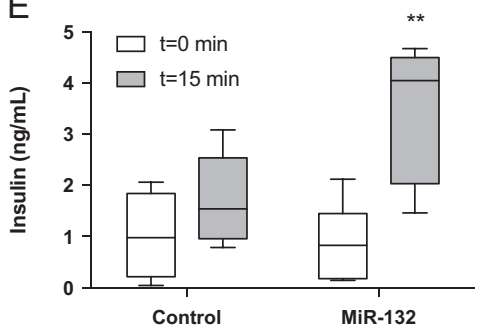

G

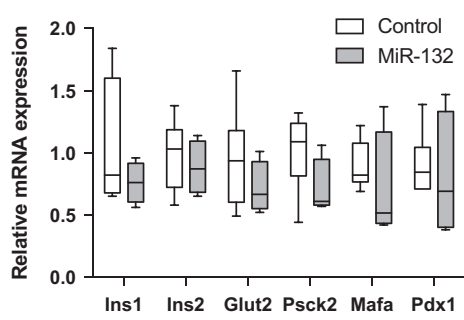

B $\quad \rightarrow$ Control $\quad-$ MiR-132
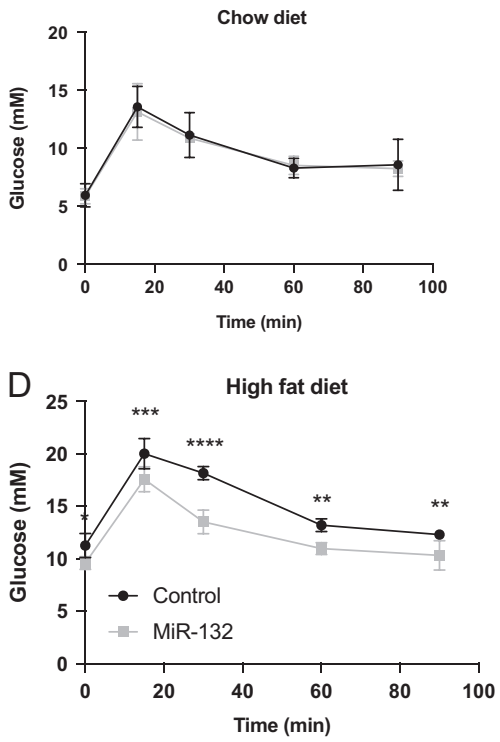

$\mathrm{F}$

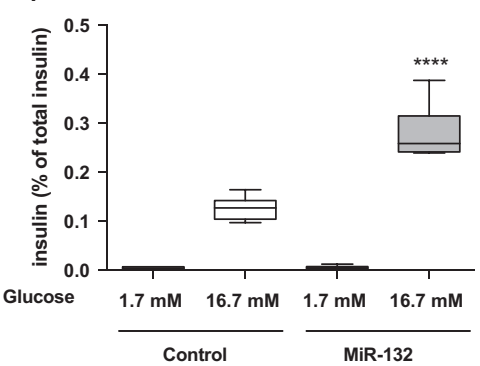

$\mathrm{H}$

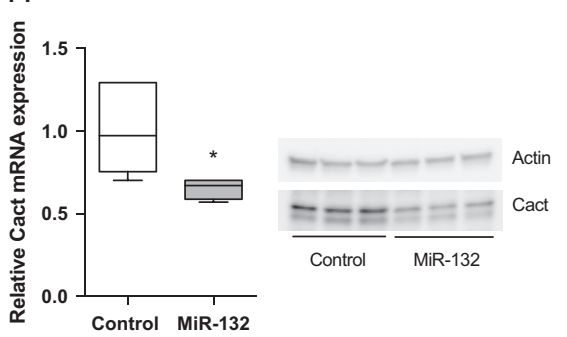

Figure 3

Impact of miR-132 overexpression in beta cells on glucose homeostasis. (A) Body weights of AAV8-RIP-GFP control and AAV8-RIP-miR132treated mice $(n=6)$ during chow and high-fat diet (HFD) feeding. (B) AAV8-RIP-miR132-treated mice showed similar glucose levels during fasting or after oral glucose bolus as control mice fed a chow diet $(n=6)$. (C) Insulin levels at 0 and $15 \mathrm{~min}$ after oral glucose bolus were similar between the two groups $(n=6)$. (D) Oral glucose tolerance testing showed improved glucose tolerance in AAV8-RIP-miR-132-treated mice after 4 weeks of high-fat diet $(n=6)$. (E) Analysis of insulin levels at 0 and $15 \mathrm{~min}$ after oral glucose bolus showed increased insulin secretion in mice overexpressing miR-132 after the glucose bolus ( $n=6)$. (F) Ex vivo analysis of glucose-stimulated insulin secretion showed increased insulin secretion at $16.7 \mathrm{mM}$ glucose in miR-132-overexpressing islets $(n=6)$. (G) Isolated islets of AAV8-RIP-miR132-treated mice showed normal gene expression of beta cell-related genes $(n=4-6)$. (H) Increased expression of miR-132 coincided with reduced expression of CACT mRNA and protein levels $(n=4-6)$. 
or beta cell function, such as insulin, glucose transporter 2 (Glut2), prohormone convertase 2 (Psck2), MAF bZIP transcription factor $A$ (Mafa) or pancreatic and duodenal homeobox 1 ( $P d x 1)$ were similar between groups (Fig. 3G). Gene expression and protein levels of the miR-132 target carnitine acyl-carnitine translocase (CACT) (Soni et al. 2014) was decreased in islets of AAV-RIP-miR132-injected animals (Fig. 3H).

\section{Increased beta cell proliferation in mice overexpressing mir-132}

Overexpression of miR-132 in dispersed rat islet cells has been shown to increase beta cell proliferation in vitro (Nesca et al. 2013). In order to determine whether overexpression of miR-132 in vivo also lead to increased beta cell proliferation, beta cell proliferation was studied in the AAV-RIP-miR132 and control mice after 2 weeks of high-fat diet feeding using BrdU incorporation. Overexpression of miR-132 leads to 2.4-fold increase in BrdU+ beta cell (Fig. 4A and B). In agreement with this, we found increased expression levels of the proliferation marker Ki67 in isolated islets from AAV-RIP-miR132 mice fed a high-fat diet for 4 weeks (Fig. 4C). Although gene expression levels of the previously identified miR-132 target retinoblastoma protein $(R b)$ (Park et al. 2011) were similar in both groups (1.0 \pm 0.5 relative expression in control islets vs $1.2 \pm 0.3$ relative expression in miR-132 islets; $P=0.48$ ), protein analysis revealed decreased $\mathrm{RB}$ protein levels in islets of miR-132 treated mice (Fig. 4D, E). To determine whether the increased proliferation resulted in increased beta cell mass, beta cell area was analyzed. However, the beta cell area did not significantly differ between the groups $(0.84 \pm 0.29 \%$ beta cell area in control islets vs $1.18 \pm 0.38 \%$ beta cell area in miR-132 islets; $n=4 ; P=0.2$ ).

\section{Discussion}

Our data show that AAV8-mediated gene transfer of miR-132 to beta cells improves beta cell function in mice in response to a high-fat diet. We found significantly increased

A
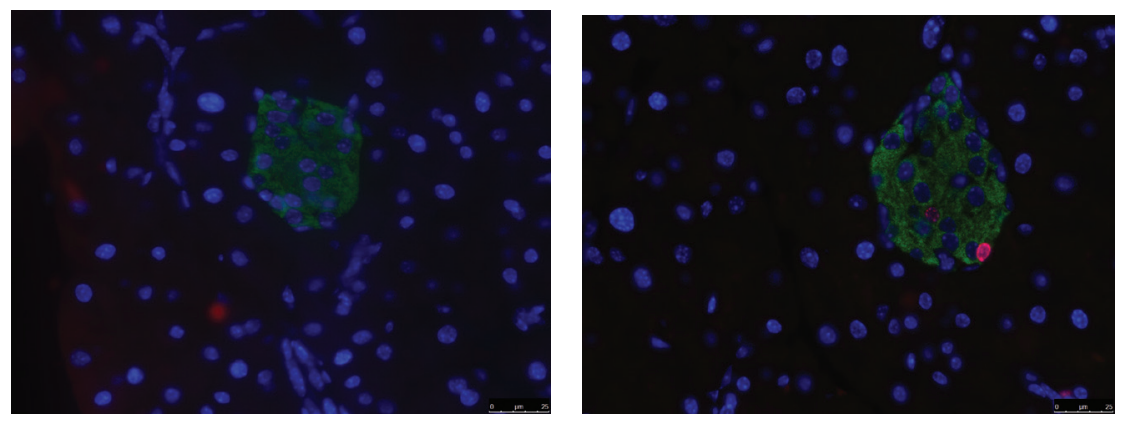

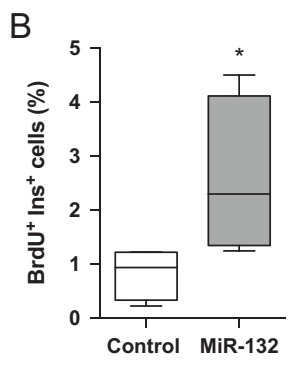

D

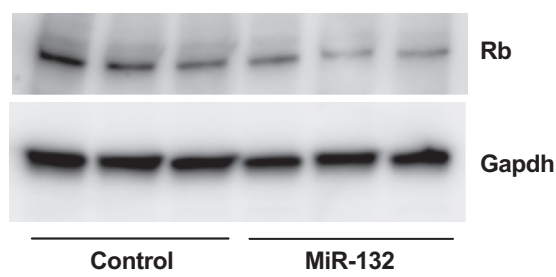

C

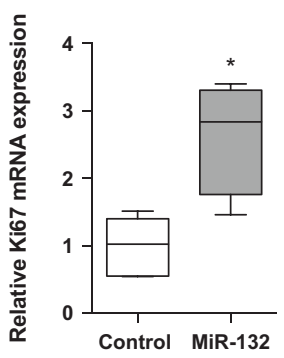

E

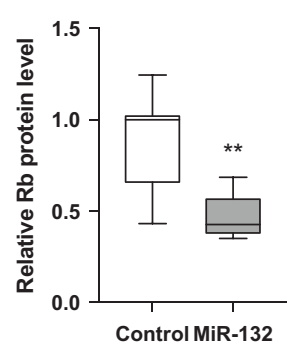

Figure 4

Signs of increased proliferation in beta cells of AAV8-RIP-miR132-treated mice. (A) Pancreatic sections of control or AAV8-RIP-miR-132-treated mice stained using immunofluorescence for insulin (green) and BrdU (red). (B) Percentage of BrdU-positive beta cells in pancreata of control and AAV8-RIP-miR-132 mice $(n=4)$. (C) Isolated islets of AAV8-RIP-miR132-treated mice showed increased ki67 gene expression ( $n=4-6)$. (D) Decreased RB protein levels in isolated islets of AAV8-RIP-miR132-treated mice, of which the quantification is shown in (E) $(n=6)$. 
glucose-stimulated insulin secretion and enhanced beta cell proliferation in mice treated with the dsAAV8-RIP-miR132 construct. These data indicate that miR-132 is a potential target to improve beta cell dysfunction during obesity.

Although overexpression of miR-132 improves insulin secretion in vitro, mice glucose homeostasis remained unaltered in chow-fed mice overexpressing miR-132 indicating that the risk on hypoglycemia is low. Mice treated with dsAAV-RIP-miR132, however, did show improved insulin secretion during high-fat diet feeding. Recent findings identified CACT as miR-132 target in beta cells (Soni et al. 2014). CACT is a transporter involved in transporting long-chain acylcarnitines into the mitochondria for $\beta$-oxidation (Wang et al. 2011). Downregulation of CACT results in an accumulation of fatty acyl-carnitines, which enhances insulin secretion. Addition of long-chain acyl-carnitines to beta cells stimulated insulin secretion; an effect that was enhanced by CACT downregulation (Soni et al. 2014). This could explain our finding that only during increased fatty acid influx, as achieved by the high-fat diet, insulin secretion was increased in the miR-132 overexpressing beta cells.

In this study, we chose to apply beta cell-specific gene therapy to evade possible side effects of miR-132 overexpression in non-beta cells. miR-132 has previously found to be involved in facilitating pathological angiogenesis in tumors (Anand et al. 2010) and is overexpressed in pancreatic adenocarcinomas (Park et al. 2011). In the pancreatic cancer cell line PAN-1, overexpression of miR-132 leads to decreased expression of the tumor suppressor $\mathrm{RB}$, leading to increased proliferation (Park et al. 2011). No difference in expression of $R b$ mRNA in islets of dsAAV8-RIP-miR132-treated mice was found, which could be due to the relative high gene expression of $R b$ in alpha cells compared to beta cells (Kutlu et al. 2009). Protein levels of RB, however, were decreased in islets overexpressing miR-132. Interestingly, exendin-4, a GLP-1 agonist known to induce beta cell proliferation in mice, has been shown to decrease RB expression. Further study revealed that this decreased $\mathrm{Rb}$ expression is necessary for the beta cell proliferation stimulating effect of exendin-4 (Cai et al. 2014). GLP-1 agonists increase miR-132 expression in beta cells (Shang et al. 2015), suggesting that miR-132 plays a central role in the adaptive beta cell response to obesity and GLP-1. Although we found increased BrdU incorporation and increased Ki67 expression in islets of dsAAV8-RIP-miR132-treated mice after high-fat feeding indicating increased beta cell proliferation, beta cell area was not significantly different between the groups. The high variation in beta cell area within the groups, the small group size and the relatively short period of high-fat diet could potentially explain this discrepancy.

Unfortunately, it was not possible to identify miR-132 targets in our setting due to the difficulty to isolate pure beta cells together with the fact that miRNAs often induce only small changes in the expression of single direct targets (Guo et al. 2010). However, our study does show that the physiological impact of miRNAs in beta cells can be successfully studied in vivo using the AAV8-mediated gene transfer system. This system could potentially help to identify the physiological roles of the over 800 miRNAs, which recent ultra-high-throughput sequencing have revealed to be expressed in the endocrine pancreas (Kameswaran et al. 2014).

During the last years, the importance of miRNAs in the control of beta cell function, proliferation and identity has become clear. Several microRNAs, such as, miR-375 and miR-184 have been identified as crucial regulators of adaptive beta cell expansion, whereas miR-7a regulates insulin secretion. Our study shows the beneficial effects of miR-132 overexpression in the setting of obesity and identifies miR-132 or its downstream targets as therapeutic targets to improve beta cell function.

\section{Declaration of interest}

The authors declare that there is no conflict of interest that could be perceived as prejudicing the impartiality of the research reported.

\section{Funding}

This research was funded by the Dutch Diabetes Research Foundation (Grant number: 2009.80.114) and the EU FP7 (Marie Curie, International reintegration grant, MiRT2DM).

\section{Author contribution statement}

$\mathrm{N} L \mathrm{M}$, J K and J K K designed the experiments. N L M, R H and J K K performed the experiments and analyzed the data. J K K wrote the manuscript. All authors revised the article and approved the final version.

\section{Acknowledgement}

The authors thank Angelika Jurdinzki for assistance with histology. (c) 2019 Society for Endocrinology Published by Bioscientifica Ltd. Printed in Great Britain 


\section{References}

Anand S, Majeti BK, Acevedo LM, Murphy EA, Mukthavaram R, Scheppke L, Huang M, Shields DJ, Lindquist JN, Lapinski PE, et al. 2010 MicroRNA-132-mediated loss of p120RasGAP activates the endothelium to facilitate pathological angiogenesis. Nature Medicine 16 909-914. (https://doi.org/10.1038/nm.2186)

Bartel DP 2004 MicroRNAs: genomics, biogenesis, mechanism, and function. Cell 116 281-297. (https://doi.org/10.1016/S00928674(04)00045-5)

Belgardt B-F, Ahmed K, Spranger M, Latreille M, Denzler R, Kondratiuk N, von Meyenn F, Villena FN, Herrmanns K, Bosco D, et al. 2015 The microRNA-200 family regulates pancreatic beta cell survival in type 2 diabetes. Nature Medicine 21 619-627. (https://doi.org/10.1038/ nm.3862)

Brunham LR, Kruit JK, Pape TD, Timmins JM, Reuwer AQ, Vasanji Z, Marsh BJ, Rodrigues B, Johnson JD, Parks JS, et al. 2007 Beta-cell ABCA1 influences insulin secretion, glucose homeostasis and response to thiazolidinedione treatment. Nature Medicine 13 340-347. (https://doi.org/10.1038/nm1546)

Cai EP, Luk CT, Wu X, Schroer SA, Shi SY, Sivasubramaniyam T, Brunt JJ, Zacksenhaus E \& Woo M $2014 \mathrm{Rb}$ and p107 are required for alpha cell survival, beta cell cycle control and glucagon-like peptide-1 action. Diabetologia 57 2555-2565. (https://doi.org/10.1007/s00125-0143381-y)

Esguerra JLS, Bolmeson C, Cilio CM \& Eliasson L 2011 Differential glucose-regulation of microRNAs in pancreatic islets of non-obese type 2 diabetes model Goto-Kakizaki rat. PLoS ONE 6 e18613. (https:// doi.org/10.1371/journal.pone.0018613)

Grimm D, Streetz KL, Jopling CL, Storm TA, Pandey K, Davis CR, Marion P, Salazar F \& Kay MA 2006 Fatality in mice due to oversaturation of cellular microRNA/short hairpin RNA pathways. Nature 441 537-541. (https://doi.org/10.1038/nature04791)

Guo H, Ingolia NT, Weissman JS \& Bartel DP 2010 Mammalian microRNAs predominantly act to decrease target mRNA levels. Nature 466 835-840. (https://doi.org/10.1038/nature09267)

Jimenez V, Ayuso E, Mallol C, Agudo J, Casellas A, Obach M, Muñoz S, Salavert A \& Bosch F 2011 In vivo genetic engineering of murine pancreatic beta cells mediated by single-stranded adeno-associated viral vectors of serotypes 6, 8 and 9. Diabetologia 54 1075-1086. (https://doi.org/10.1007/s00125-011-2070-3)

Kahn SE, Montgomery B, Howell W, Ligueros-Saylan M, Hsu CH, Devineni D, McLeod JF, Horowitz A \& Foley JE 2001 Importance of early phase insulin secretion to intravenous glucose tolerance in subjects with type 2 diabetes mellitus. Journal of Clinical Endocrinology and Metabolism 86 5824-5829. (https://doi.org/10.1210/ jcem.86.12.8105)

Kameswaran V, Bramswig NC, McKenna LB, Penn M, Schug J, Hand NJ, Chen Y, Choi I, Vourekas A, Won K-J, et al. 2014 Epigenetic regulation of the DLK1-MEG3 microRNA cluster in human type 2 diabetic islets. Cell Metabolism 19 135-145. (https://doi.org/10.1016/j. cmet.2013.11.016)

Kutlu B, Burdick D, Baxter D, Rasschaert J, Flamez D, Eizirik DL, Welsh N, Goodman N \& Hood L 2009 Detailed transcriptome atlas of the pancreatic beta cell. BMC Medical Genomics 2 3. (https://doi. org/10.1186/1755-8794-2-3)

Latreille M, Hausser J, Stützer I, Zhang Q, Hastoy B, Gargani S, KerrConte J, Pattou F, Zavolan M, Esguerra JLS, et al. 2014 MicroRNA-7a regulates pancreatic $\beta$ cell function. Journal of Clinical Investigation 124 2722-2735. (https://doi.org/10.1172/JCI73066)

Merglen A, Theander S, Rubi B, Chaffard G, Wollheim CB \& Maechler P 2004 Glucose sensitivity and metabolism-secretion coupling studied during two-year continuous culture in INS-1E insulinoma cells. Endocrinology 145 667-678. (https://doi. org/10.1210/en.2003-1099)
Montane J, Bischoff L, Soukhatcheva G, Dai DL, Hardenberg G, Levings MK, Orban PC, Kieffer TJ, Tan R \& Verchere CB 2011 Prevention of murine autoimmune diabetes by CCL22-mediated Treg recruitment to the pancreatic islets. Journal of Clinical Investigation 121 3024-3028. (https://doi.org/10.1172/ JCI43048)

Nathwani AC, Gray JT, Ng CYC, Zhou J, Spence Y, Waddington SN, Tuddenham EGD, Kemball-Cook G, McIntosh J, Boon-Spijker M, et al. 2006 Self-complementary adeno-associated virus vectors containing a novel liver-specific human factor IX expression cassette enable highly efficient transduction of murine and nonhuman primate liver. Blood 107 2653-2661. (https://doi.org/10.1182/blood2005-10-4035)

Nesca V, Guay C, Jacovetti C, Menoud V, Peyot M-L, Laybutt DR, Prentki M \& Regazzi R 2013 Identification of particular groups of microRNAs that positively or negatively impact on beta cell function in obese models of type 2 diabetes. Diabetologia 56 2203-2212. (https://doi.org/10.1007/s00125-013-2993-y)

Park J-K, Henry JC, Jiang J, Esau C, Gusev Y, Lerner MR, Postier RG, Brackett DJ \& Schmittgen TD 2011 miR-132 and miR-212 are increased in pancreatic cancer and target the retinoblastoma tumor suppressor. Biochemical and Biophysical Research Communications $\mathbf{4 0 6}$ 518-523. (https://doi.org/10.1016/j.bbrc.2011.02.065)

Perley MJ \& Kipnis DM 1967 Plasma insulin responses to oral and intravenous glucose: studies in normal and diabetic sujbjects. Journal of Clinical Investigation 46 1954-1962. (https://doi.org/10.1172/ JCI105685)

Poy MN, Eliasson L, Krützfeldt J, Kuwajima S, Ma X, MacDonald PE, Pfeffer S, Tuschl T, Rajewsky N, Rorsman P, et al. 2004 A pancreatic islet-specific microRNA regulates insulin secretion. Nature $\mathbf{4 3 2}$ 226-230. (https://doi.org/10.1038/nature03076)

Poy MN, Hausser J, Trajkovski M, Braun M, Collins S, Rorsman P, Zavolan M \& Stoffel M 2009 miR-375 maintains normal pancreatic alpha- and beta-cell mass. PNAS 106 5813-5818. (https://doi. org/10.1073/pnas.0810550106)

Reed SE, Staley EM, Mayginnes JP, Pintel DJ \& Tullis GE 2006 Transfection of mammalian cells using linear polyethylenimine is a simple and effective means of producing recombinant adeno-associated virus vectors. Journal of Virological Methods 138 85-98. (https://doi. org/10.1016/j.jviromet.2006.07.024)

Salvalaggio PRO, Deng S, Ariyan CE, Millet I, Zawalich WS, Basadonna GP \& Rothstein DM 2002 Islet filtration: a simple and rapid new purification procedure that avoids ficoll and improves islet mass and function. Transplantation $\mathbf{7 4}$ 877-879. (https://doi.org/10.1097/01. TP.0000028781.41729.5B)

Shang J, Li J, Keller MP, Hohmeier HE, Wang Y, Feng Y, Zhou HH, Shen X, Rabaglia M, Soni M, et al. 2015 Induction of miR-132 and miR-212 expression by glucagon-like peptide 1 (GLP-1) in rodent and human pancreatic $\beta$-cells. Molecular Endocrinology 29 1243-1253. (https://doi. org/10.1210/me.2014-1335)

Soni MS, Rabaglia ME, Bhatnagar S, Shang J, Ilkayeva O, Mynatt R, Zhou Y-P, Schadt EE, Thornberry NA, Muoio DM, et al. 2014 Downregulation of Carnitine acyl-carnitine translocase by miRNAs 132 and 212 amplifies glucose-stimulated insulin secretion. Diabetes 63 3805-3814. (https://doi.org/10.2337/db13-1677)

Tattikota SG, Rathjen T, McAnulty SJ, Wessels H-H, Akerman I, van de Bunt M, Hausser J, Esguerra JLS, Musahl A, Pandey AK, et al. 2014 Argonaute2 mediates compensatory expansion of the pancreatic $\beta$ cell. Cell Metabolism 19 122-134. (https://doi.org/10.1016/j. cmet.2013.11.015)

Wang Z, Zhu T, Rehman KK, Bertera S, Zhang J, Chen C, Papworth G, Watkins S, Trucco M, Robbins PD, et al. 2006 Widespread and stable pancreatic gene transfer by adeno-associated virus vectors via different routes. Diabetes 55 875-884. (https://doi.org/10.2337/ diabetes.55.04.06.db05-0927) 
Wang G-L, Wang J, Douglas G, Browning M, Hahn S, Ganesh J, Cox S, Aleck K, Schmitt ES, Zhang W, et al. 2011 Expanded molecular features of carnitine acyl-carnitine translocase (CACT) deficiency by comprehensive molecular analysis. Molecular Genetics and Metabolism 103 349-357. (https://doi.org/10.1016/j. ymgme.2011.05.001)

Zhao E, Keller MP, Rabaglia ME, Oler AT, Stapleton DS, Schueler KL, Neto EC, Moon JY, Wang P, Wang I-M, et al. 2009 Obesity and genetics regulate microRNAs in islets, liver, and adipose of diabetic mice. Mammalian Genome 20 476-485. (https://doi.org/10.1007/ s00335-009-9217-2)

Zolotukhin S, Byrne BJ, Mason E, Zolotukhin I, Potter M, Chesnut K, Summerford C, Samulski RJ \& Muzyczka N 1999 Recombinant adeno-associated virus purification using novel methods improves infectious titer and yield. Gene Therapy 6 973-985. (https://doi. org/10.1038/sj.gt.3300938)

Received in final form 2 October 2018

Accepted 8 October 2018

Accepted Preprint published online 9 October 2018
(C) 2019 Society for Endocrinology Published by Bioscientifica Ltd. 